\begin{tabular}{|c|l|}
\hline \multicolumn{2}{|c|}{ Access this article online } \\
\hline Quick Response Code: & $\begin{array}{l}\text { Website: } \\
\text { www.annalsafrmed.org }\end{array}$ \\
\hline & \\
\hline
\end{tabular}

\title{
Intramuscular cysticercosis - The solitary reaper
}

\author{
Raman Pratap Singh \\ Department of Radiodiagnosis, MM Institute of Medical Sciences and Research, Mullana, Ambala, India
}

Correspondence to: Dr. Raman Pratap Singh, Department of Radiodiagnosis, MM Institute of Medical Sciences and Research, Mullana, Ambala, Haryana, India. E-mail: drramanchawla7@gmail.com

\begin{abstract}
Occurrence of solitary intramuscular cysticercosis without involvement of the central nervous system is rare. We report a case of solitary cysticercosis of the brachioradialis muscle in a 35-year-old woman who presented with discomfort and pain in the right elbow and arm after trivial trauma. There were no systemic or neurological features.

Keywords: Intramuscular cysticercosis, magnetic resonance imaging, solitary

\section{Résumé}

Présence de la cysticercose intramusculaire solitaire sans implication du système nerveux central est rare. Nous rapportons un cas de cysticercose solitaire du muscle supinateur chez une femme de 35 ans qui a présenté avec gêne et douleur dans le coude droit et le bras après un traumatisme trivial. Il n'y a pas de caractéristiques systémiques ou neurologiques.
\end{abstract}

Mots-clés : Cysticercose intramusculaire, imagerie par résonance magnétique

\section{Case Report}

A 35-year-old woman had hurt her elbow and upper arm in a fall at home about a week back. X-rays of the arm and the forearm were normal with no evidence of fracture or dislocation. Her clinical examination was also normal. She was given oral analgesic medication, but there was no improvement in the pain and discomfort. Subsequently she underwent magnetic resonance imaging (MRI), which revealed small oval cystic foci of T1-hypointensity measuring $12 \times 10 \mathrm{~mm}$ in size in the right brachioradialis muscle [black arrow in Figure 1]. It was found to be oriented along the direction of the muscle fibers. A small T1-hyperintense eccentric focus was noted within the cystic lesion, representing the scolex [solid white arrow in Figure 1].

Perilesional muscles and fat planes were normal. Ipsilateral distal humerus, radius, and ulna showed normal cortical and marrow substances. These imaging findings were diagnostic of intramuscular cysticercosis.

The patient was put on oral albendazole $(15 \mathrm{mg} / \mathrm{kg})$ for 4 weeks. After completion of the treatment, the pain and discomfort had completely subsided. Follow-up ultrasound of the right arm showed no residual lesion.

\section{Discussion}

Cysticercosis is no longer a disease of the third world, but it is increasingly being reported from the devolved world due to influx of immigrants. The encysted larva can lodge in the nervous system, subcutaneous tissues, eyes, viscera, muscles, and many other organs of the human body. Most of the skin and intramuscular lesions coexist with central nervous system involvement. 


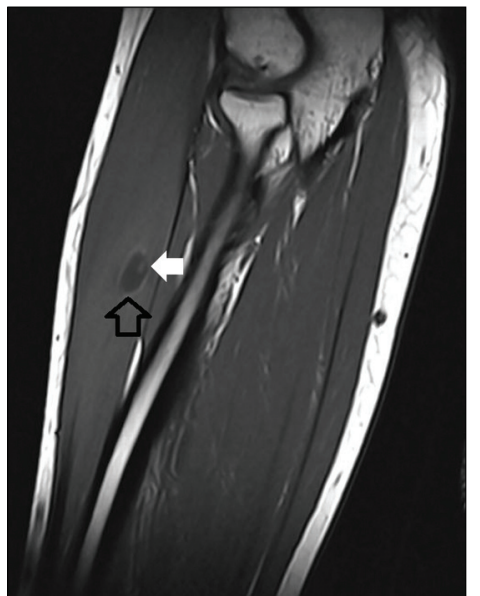

Figure 1: T1-weighted magnetic resonance imaging in the sagittal plane showing a small oval cystic lesion measuring $12 \times 10 \mathrm{~mm}$ in size in the right brachioradialis muscle (black arrow) oriented in the plane of the muscle fibers with a small eccentric focus noted within the cystic lesion, representing the scolex (solid white arrow)

Solitary cysticercosis of muscle without involvement of the central nervous system is a rare entity and a few case reports have been reported in the literature. ${ }^{[1,2]}$ These solitary presentations of cysticerci are confusing as they present with vague misleading symptoms and there are no pathognomonic clinical symptoms. In such difficult clinical scenarios, radiology-based investigations such as ultrasound and MRI play a pivotal role in diagnosis. The differential of solitary cysticercosis of the muscle should always be considered in the clinical scenario of intractable pains of the limbs.

\section{References}

1. Ogilvie CM, Kasten P, Rovinsky D, Workman KL, Johnston JO. Cysticercosis of the triceps-An unusual pseudotumor: Case report and review. Clin Orthop Relat Res 2001;382:217-21.

2. Abdelwahab IF, Klein M], Hermann G, Abdul-Quader M. Solitary cysticercosis of the biceps brachii in a vegetarian: $A$ rare and unusual pseudotumor. Skeletal Radiol 2003;32:424-8.

Cite this article as: Singh RP. Intramuscular cysticercosis The solitary reaper. Ann Afr Med 2014;13:53-4.

Source of Support: Nil, Conflict of Interest: None declared.

Announcement

Android App

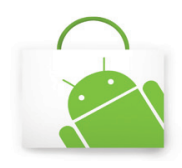

Download

Android applicati
A free application to browse and search the journal's content is now available for Android based mobiles and devices. The application provides "Table of Contents" of the latest issues, which are stored on the device for future offline browsing. Internet connection is required to access the back issues and search facility. The application is compatible with all the versions of Android. The application can be downloaded from https:// market.android.com/details?id=comm.app.medknow. For suggestions and comments do write back to us. 